\title{
Teacher to Student Epistemological Interaction in the Contemporary Paradigm of University Education
}

\author{
Irina Charikova ${ }^{1}$, Victor Zhadanov ${ }^{2}$
}

\begin{abstract}
The relevance of the problem under study is conditioned by the socially important need of the contemporary university education to train highly qualified personnel in all directions of activity, to form and develop a professional person of a high intellectual, moral and spiritual culture. The objective of the paper consists in giving theoretical grounds for the significant aspects of pedagogical implementation of training technologies and methods that are associated with the humanitarian vectors of generating the personal, "living" knowledge in the course of epistemic transformation of the content-related and essential parameters of interaction between subjects of the educational process at higher school. The leading approach to studying this problem was the activity-based one. It is consistently implemented in the competency-based paradigm of the contemporary higher education and it implies the epistemologically centered transformation of the pedagogical functions range of a university teacher. This would become a qualitative foundation for the new level of organizing the project, creative, scientific and research activities of students within the problem-solving and reflexive discourse of working within the group and interactive communication. In particular, in the contemporary university education paradigm, the epistemological interaction of teachers and students is to be the fact of the creative availability of intellectual relationships in the co-being reality of gaining the personally important, "living" knowledge. It acts as a factor of productive performance for the project-oriented epistemic technologies of forming a professional person of a high intellectual and spiritual culture. So it implies a generalized ability of a teacher to mentally activate the motivation and need sphere of the learners' personality pushing it towards intellectual openness to new knowledge and towards sensible responsible actions in the constructive context of project image of being. The materials of the paper can be of use for higher school teachers who are actual and effective participants in the innovation process of cognitive transformation that the contemporary university's mission undergoes, it being implemented within the epistemological paradigm "education through scientific research, heuristic cooperation and creative discoveries".
\end{abstract}

Keywords: epistemology, "living" knowledge, personal development, knowledge acquisition, projecting, problem-solving, pedagogical projection.

\section{Introduction}

In all times of cultural and historical development of the society, the university education has been called on to open up new and reassuring horizons for development and selfdevelopment of the learners' personality. It ensures this by introducing the knowledge about the world, the others, the man himself as a professional sphere employee and making them more

\footnotetext{
${ }^{1}$ Assoc. Prof., Candidate of Pedagogy, Orenburg State University, irnic@bk.ru

${ }^{2}$ Prof., Doctor of Engineering, Head of the Department, Orenburg State University, vikira@list.ru
} 
popular.

The rapid development of scientific and technical advance creates an increasingly higher volume of educational information as the "ready-made" information, data, knowledge. As a consequence, it is often the case when a better student can be (and proves to be) the one who has a better memory for the "formal", "ready-made" knowledge - the one who can handle correctly the growing quantity and kinds of accompanying data - and not at all his study peer having a vast luggage of personally centered knowledge, the "living", lived through and experienced one by the fact of an intellectual effort (Wedman \& Wang, 2005, Stamou, 2017). The traditional fact of "solid" acquisition of a fundamental knowledge store has a no doubt important, however, not the determining meaning for a successful educational training and the subsequent professional activity of the future professional (Kopish, 2016; Lafer \& Aydin, 2012; Yigit, 2017). This is so because the current labor market badly needs specialists tending to continuous self-education, being able to think, analyze, generalize independently, to obtain and creatively apply the knowledge and, ideally, to build their own knowledge in line with the certain properties of the problem-solving situation changing (Demirhan \& Yücel, 2016; Leek, 2016).

With regard to this, the contemporary Russian researchers quite fairly provide grounds for "the need of total transition from the previously habitual scheme "subject- and informationbased" education (the "knowledge by experience" education, reproductive one, mainly pragmatic and standardized one) to the "business, professional and prospective" education (Lushchikov, 2012). In its name-bearing typology, a "noticeable place" belongs to the phenomenon of "cgatyrevreative education" (Efremova, 2010) which is oriented to "consolidating" in the future specialist's "professional conscience of attitudes to look for innovations, to analyze problems and solution options" that help "turning the knowledge into the potential of thinking and selfdevelopment". It is this that takes place in the epistemological imperative of the contemporary educational interaction at higher school: "Comprehending not only what is known but also what is unknown, while productively mastering the expanding cognitive area of knowledge about ignorance" (Ghenisaretskiy, 1994).

A creative person always has an essentially insatiable need of acquiring and creating new knowledge, ideas, ideals, images, working out new behavior and activity models and forms. It is the qualitatively increasing human needs that are a creative source of development of the project knowledge which is innovational in its constructive focus on the future and acts both as an 
intellectual foundation and the educational matrix of the progressive development of the society.

\section{Literature Review}

In the foreign humanitarian thought, such an important epistemological reference point of the contemporary university education in the changing world was most prominently worded by R. Barnett, professor of the Institute of education, London university. According to him, the today's university "is designed not only to multiply the schemes of understanding the world but also to teach more or less comfortable life under the radical uncertainty... The university generates super-complexity and teaches us to live with it" (Barnett, 2008, p. 46).

Moreover, today, there arises a threatening educational problem of "information overflow" in the contemporary students, exactly corresponding to the known saying by K. Prutkov "One cannot embrace the unembraceable!". The problem may "fatally" border on the "physical limits" of the relevant opportunities of human brain (Barnett, 2008, p. 46).

Hence, at the time of globalism becoming firmly established, the universities can efficiently perform their high mission only in the case if they are not only social and cultural translators of the "ready-made" knowledge but if they also turn into actual centers of producing the "new", "living", personally significant knowledge and one promoting the productive life in conditions of continuously changing "super-complicated" world, one that exists by generation, first of all, at humanitarian centered basic segments of the university's educational interaction: "teacher - student", "student - group - teacher".

With regard to this, the educational process at the Russian higher school today is viewed as an academic form of non-linear, individually centered and variative interaction (Makarova, 2014, Timova, 2014). It is performed in the project and environment conditions of humanitarian support and it is aimed at multiplying the intellectual (human, knowledge-based, intellectrelated) capital of a personality in order to further use it efficiently in a constructive activity (Bogoslovskiy \& Glubokova, 2008, Moiseev, 1993). This is so because knowledge always exists just in a certain kind of busy activity, it always "exists in the processes of usage generating it" (Gromyko, 2011, p. 8) and it fundamentally has no limitations in all scopes and at all angles of its "life-related" measurement and creative understanding.

The above factors of the comprehensive pedagogical support for epistemological (epistemic) reference points of the profound upgrade of the Russian higher education directly correlate with the general directives on innovation transformation ("the transformation") of the 
Russian education in the $21^{\text {st }}$ century. They have been worded by academician D.I. Feldshtein $(1994,2012)$ and they are associated with focused formation of a "new" man who is capable of productive life activity in the drastically changed "time/space" of his being, who is internally prepared for "solving the complicated, objectively facing him non-standard tasks containing a huge amount of uncertainties" while at the same keeping "all the best human qualities and human potential" (Feldshtein, 2012, p. 1).

While fairly pointing out the fact that "the classical pedagogical paradigm is objectively exhausted" under the present-day rapidly changing life conditions, D.I. Feldshtein calls on the contemporary Russian education "to prepare a creative person, a creatively thinking one" who is oriented not to "imitation" and "repetition" of a having already occurred experience but rather to "creation of a new, one's own way". This implies, in particular, forming the ability to not only acquire the necessary scope of the existing knowledge but also to "adopt a creative attitude towards it while also participating in their further elaboration" (Charikova, 2016, p. 29).

Moreover, there is an epistemically important moral and esthetic component that stands out in the detailed register of the "best human qualities" to be programmed. It characterizes the desirable (due) image of a modern young person - an intellectual demiurge and a dedicated creator of the new knowledge: the person "likes change" and is ready to "bravely face the completely unforeseen situations" (Feldshtein, 2012, p. 9). Directly associated with the relevant style of the upbringing influence, this statement, on the one hand, proceeds with justifying the imperishably relevant "enlightment" task of education which was worded by I. Kant as an imperative "Have the courage to use your own reason!" On the other hand, in a similarly important cognitive respect, it accompanies the desirable condition of an approving acceptance by the young people of broadly understood life "change" (not in the latest turn as "difficulties", "impediments", "obstacles"). Here it can be spoken about pedagogically mediated progress of learners towards an inspiring constancy of a "stable" condition of the "joy of thinking", of expecting the onset of the "fair and honest joy of thought" conditioned by work, as worded by M.K. Mamardashvili (2000). This is conformable to nature to the limit and so a profoundly natural condition.

The above is the source of problem-solving and epistemological foundations of pedagogical organization of educational subjects' interaction. Equally, the problem-solving project character of epistemic technologies of the higher school students' personal growth is 
justified which is located within the theoretical, methodological and practical plane of ideals and ideas in "thought- and activity-based pedagogy" (Gromyko, 2011; Shchedrovitskiy, 2001). Here it is the learning of radically new, epistemic technologies of working with knowledge that goes to the foreground: students have not only to remember something, they have - they are called on by the circumstances of time - to understand how knowledge emerges and in which way it can be used.

This is why in the reference points of the competency-based approach being established, the educational and pedagogical functions range of a higher education institution teacher is transformed essentially. The requirements for his didactic competency are increased, in particular, ones in the aspect of students' cognitive activity support within the information educational environment using the techniques of critical thinking development technology, problem-solving questions and assignments (Dakhin, 2010; Tarman \& Acun, 2010; Tarman, 2016). This implies a transition to a qualitatively higher level of the teacher's mastery of the learners' project, creative, scientific and research activity organization technologies to be applied in the personally developing environment of group interaction (coaching and workshops) and interactive communication (moderating and facilitating). Other spheres include the content- and meaning-related cognitions of critical thinking, problem-solving and reflexive learning and metacognitive activity (Lektorskiy et al., 2014) that are implemented within the educational chronotope of teachers and students' joint epistemological being (co-working, co-operation) (Lazarev, 2015).

\section{Methodological Framework}

Generalizing the above, the prevailing objectives of our research can be made more precise: developing the conceptual bases for implementing the higher school students' project activity within the personality developing space of educational epistemology (The humanitarian mission of supporting the project activity in a multi-national educational space, 2008). In terms of tasks, this implies having to conduct a focused research exploration in further expansion area of conceptual opportunities opened up by the pedagogical toolkit in the process of actualizing the epistemic foundations for the contemporary university students' educational activity, the foundations being associated with project vectors and personal development technologies of learners as the actual subjects of "living" (personal) knowledge.

Epistemological transformation of the educational content and pedagogical meanings of 
students' project activity which acts as a determining factor in forming a "new" type specialist emphasizes the effective foundations of the competency- and activity-based methodology. This methodology is axiologically implemented within the personality developing context of heuristically focused methods, tools and techniques that generate ascending to professional and life-related results and meanings of being.

\section{Results and Discussion}

In this research, functions range of forming a "new" professional specialist in an epistemically centered university educational interaction (which was outlined in terms of tasks and objectives) is designed to take into account within its implementation not only the developing opportunities of time-proven foreign and Russian methods and technologies for boosting a personality's creative capacities ("brainstorming", "synectics", "theory of solving the inventor's problems" etc.) but quite expectedly it relies on the cognitive and heuristic resource of communication and information technologies. They expand the space for obtaining the personally centered, "living" knowledge considerably (Karagapoltsev \& Charikova, 2016) and they act as a determining humanitarian attribution of teacher to student epistemological interaction within the contemporary "thought- and activity-based" paradigm of the university education ("episteme collection", "the method of creating problem epistemic situations", "the method of educational estheticization of the content of professional and life-related epistemes" etc.).

The provisions and vectors of thought- and activity-based pedagogy that are oriented to creating fundamentally new educational modules / structures - episteme collections which are a kind of informational "superstructures" - are highly important for this research, within the plane of higher education institution training of further specialists-innovators, creative professionalsdesigners who are able to find their bearings easily in the modern society's increasingly complicated information space. The architecture of the information support of teacher to student epistemological interaction can be presented as a model given in Figure 1. 


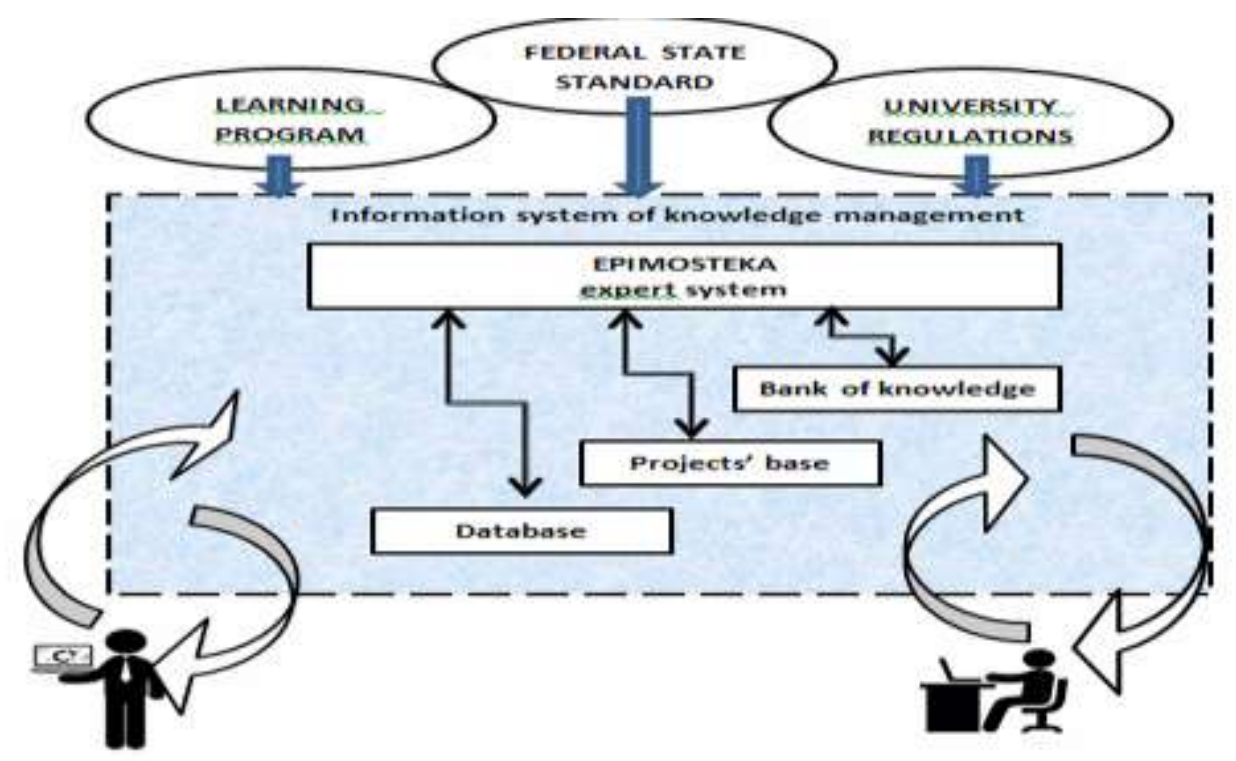

Figure 1. The architecture of information support for teacher to student epistemological interaction.

Note: The following figure and note are each adapted from Charikova (2016).

In the constructive plane of activity-based approach of the episteme collection, by "creating a bank of problems over which the entire humanity struggles", a fundamentally new cognitive focus of the learners' intellectual view is set heuristically. In particular, this involves drawing the boundaries between the "known" and the "unknown, and students are project-based oriented to mastering the new ways of individual and group work with knowledge. Thus, the "knowledge about the subject knowledge structure" is presented as the meta-knowledge, the "knowledge about ignorance", no matter in what subject form it exists (Efremova, 2010, p. 207, p. 236), which directly promotes actualizing the efforts and energies of intellectual exploration and gaining the epistemological - extremely life-relevant and profoundly personal - meanings of the being learned in the endless diversity of its cognitive interpretations.

Speaking about the gnoseological context of personal gaining the "epistemological meanings" of the being learned, it is the created availability of the "problem-solving situation" that acts as the pedagogical principle of the learners' project and research exploration. Meanwhile, the very scientific problem is understood to have a status of a "special form of knowledge", a "structural unit of scientific knowledge" which "alongside with essentially debatable and polemic functions" is viewed as a "consequence of dissociation, controversy and 
incompleteness of knowledge" - or, in fact, as the previously mentioned "knowledge about ignorance" (Mikeshina, 2005, p. 258-261). This has the most direct attitude to heuristic actualization of epistemic foundations and vectors of teacher to student interaction within the changing paradigm of the university education.

The so-called "method of educational estheticization of the content of professional and life-related epistemes" is extremely important for achieving the objectives and tasks set in this research. Here the "synectically" centered esthetic parameters range is manifested not only in the feelings of unconditional (sensual) hedonistic nature of the formal characteristics of the beauty in cognitive structures and intellectual constructs opened up (symmetry, harmony, integrity, proportionality) (Kovalenko \& Nikitina, 2012) which is actualized by the teacher in learners. It also manifests itself in situations of mental penetration into (touching at) the inviting and alluring world of the mystery, riddle, miracle to be comprehended that is happening here and now, literally "in the very eyes" of the learners while being artistically (by script-writing and acting out) built by the teacher. The point is that the tool-related (formal) category of "how?" that is associated with presentation style frequently plays a not less significant part - and perhaps a more important one too - as compared to the unshakable content-richness of the knowledge structure "what?" in the educational subjects' epistemological interaction (Bogatyrev \& Ustinova, 2008).

Hence at the initial stages of building an epistemologically centered interaction, the principal pedagogical task of a teacher consists in not only conveying to the learners an essential minimum of ready-made (formal) knowledge and teaching them to obtain the required knowledge-related information independently (to process, to filter, to invert and to integrate), but also to form their ability to turn the initial (formalized) cognitive structural nature into a new, personally important, "living" typology of knowledge in a generating way (Jones, 1986, Zianghirova, 2007).

With regard to this, possessing the generalized ability to "place the miracle inside the law" (Berezhnova, 2008) acts as a professionally important attributive feature of teachers participants of this research. It implies a pedagogical total of the relevant techniques and training methods that produce a favorable effect on raising the university teacher to student educational interaction to the level of epistemological cooperation and creativity. 


\section{Conclusion}

In their joint educational cooperation with university teachers, the today's students are actually directed towards a diverse and discernible set of cognitive epistemic units - pieces of knowledge, facts, data, information, various kinds of models and schemes, theories and techniques - that are mainly presented as the intellectual and meaning-related content-richness which is still evolving and fundamentally uncompleted.

The extent of the learners' actual and effective acquisition of the outlined epistemic fundamentals of their learning and educational activity largely depends on the extent to which the future professionals are capable of the independent cognitive reflection of the generalized cognitive units (epistemes) - whether they understand their structure, whether they can assess them in the plane of generating emergence and completing uncertainty, whether they can perform a calculation, construction, scheme drawing up etc.

In pedagogical actualization of these processes, the teacher is given a fundamentally important place. He is designed to become not only a subject of joint epistemological being which is to inspire the students, but also an undoubted authority in intellectual and life professionalism and, thus, an attractive example to imitate in the learners' eyes. As "imitating acquisition of behavior stereotypes and moral norms opens up a direct path to the sphere of the subconscious" (Timova, 2014, p. 28), therefore, this conditions the behavioral and activityrelated efficiency of the process of upbringing formation of a personality in the epistemologically centered educational interaction.

It seems no kind of the most modern technologies, methods and tools will lead to the desired educational result, or (which is the same) will allow a today's teacher to act as a fullfledged "coach" - a professional specialist at making his students intellectually succeed - unless the teacher holds a firm belief into the learners' intellectual resource, unless he possesses the optimizing hope for a favorable pedagogical forecast on the cognitive rise of the student's personality. Without these, epistemological teacher to student interaction is fundamentally impossible within the contemporary paradigm of the university education.

The questions of identifying the status for axiological dominant in teacher to student interaction within the contemporary paradigm of the university education remain debatable and beyond the scope of this paper.

Thus, teacher to student epistemological interaction in the contemporary university 
education paradigm has the following features:

- it is the fact of creative availability of intellectual relationships between the educational subjects that occur on the occasion of achieving (gaining, ascending to) a level of cognitive cobeing in personally important, "living" new knowledge having an intention for self-development; - it acts as a factor of actual performance of the learners' project activity which is associated with the project-oriented epistemic technologies of personal development, and with forming of people distinguished by a high intellectual, spiritual culture, ones who are capable of making responsible professional and daily life decisions in the constructive contexts of project image of being;

- it implies the teacher's having certain qualities that promote mental actualization of motivation and need sphere of personality with the learners in a lively, attractive, "engaging" plane of an educative mystery and riddle, provoking as an incentive the condition of a "tomorrow's joy" (A.S. Makarenko) as the desirable intellectual openness to a new knowledge and new cognitive (content- and meaning-related) worlds. 


\section{References}

Barnett, R. (2008). Understanding the University. Alma Mater, 6, 46-56.

Bogatyrev, A.I. \& Ustinova, I.M. (2008). Theoretical foundations of pedagogical modeling: essence and efficiency. URL: http://www.rusnauka.com/SND/ Pedagogica/2_bogatyrev\% 20a.i..doc.htm

Bogoslovskiy, V.I. \& Glubokova, E.N. (2008). Knowledge management in educational process of the modern university: scientific and methodological materials. - SPb.: Knizhniy Dom Ltd.

Charikova, I.N. (2016). Activity-based epistemology in teaching automated design: a study guide. - Orenburg: "University" PPC Ltd.

Dakhin, A.N. (2010). Modeling in pedagogy. Ideas and Ideals, 1(3), Vol. 2, 11-20.

Demirhan,G. \& Yücel, C. (2016). A Prediction for Teacher Commitment; Effects of Managerial Style, Burnout and Demographics. Research in Social Sciences and Technology, 1(1). http://ressat.org/index.php/ressat/article/view/2

Efremova, N.F. (2010). Forming and assessing the competences in education: a monograph. Rostov-on-Don: Arkol.

Feldshtein, D.I. (2012). Attestation of scientific personnel in pedagogical and psychological specialties. Education and Science, 10. URL: http://archive.edscience.ru/ru/article/d-ifeldshteyn

Feldshtein, D.I. (1994). Psychology of the rise of personality. Moscow: Publishing House of the International Pedagogical Academy.

Ghenisaretskiy, O.I. (1994). The activity of projecting and projective culture (Preface to the unpublished book on project culture of 1994. URL: http://www.ckp.ru/biblio /g/gen/gen_project_culture.htm

Gromyko, N.V. (2011). Activity-based epistemology and the problem of translating the theoretical knowledge in educational practice: $\mathrm{PhD}$ thesis. Moscow.

Jones, J.Ch. (1986). Methods of design. Moscow: Mir.

Kargapoltsev, S.N. \& Charikova, I.N. (2016). Epistemological angles of project activity of the university students. Bulletin of $O S U, 9,15-19$. 
Kovalenko, Yu.A. \& Nikitina L.L. (2012). Students' project activity in the educational process of higher educational institutions. Bulletin of Kazan Technological University, 20(15), 229231.

Kopish, M.A. (2016). Preparing Globally Competent Teacher Candidates Through Cross Cultural Experiential Learning. Journal of Social Studies Education Research, 7(2), 75108.

Lafer, S. \& Aydin, H. (2012). Educating for Democratic Societies: Impediments. Journal of Social Studies Education Research, 12(2), 45-70.

Lazarev, V.S. (2015). Project activity at schools: non-used opportunities. Questions of education, 3, 292-307.

Leek, J. (2016). Global citizenship education in school curricula. A Polish perspective. Journal of Social Studies Education Research, 7(2), 51-74.

Lektorskiy, V.A., Kudzh, S.A. \& Nikitina, E.A. (2014). Epistemology, science, and the human life world. Bulletin of MSTU MIREA, 2(3), 1-12.

Lushchikov, V.V. (2012). The content of designer competence of a teacher. Bulletin of the South Ural State University, 26, 82-86.

Makarova, N.S. (2014). The reflection of changes in the higher education institution educational process in the teacher's activity. Theory and Practice of Social Development, 2, 191-194.

Mamardashvili, M.K. (2000). Esthetics of views. Moscow: School of Moscow Political Research.

Mikeshina, L.A. (2005). Philosophy of science: Modern epistemology. Scientific knowledge within the dynamics of culture. Methodology of scientific research: a study guide. Moscow: Progress-Tradition: MPSI : Flinta.

Moiseev, N.N. (1993). Ascending to reason. Lectures on universal evolutionism and its applications. Moscow: Atomizdat.

Shchedrovitskiy, P.G. (2001). Lecture on design space. URL: http://www.shkp.ru/lib/archive/second/2001-1/7

Stamou, A. (2017). Knowledge management in doctoral education toward knowledge economy. International Journal of Educational Management, 31(3), 320-331.

Tarman, B. \& Acun, I. (2010). Social Studies Education and a New Social Studies Movement. Journal of Social Studies Education Research, 1(1), 1-16. 
Tarman, B. (2016). Innovation and education. Research in Social Sciences and Technology, 1(1), 77-97.

The humanitarian mission of supporting the project activity in a multi-national educational space: a study guide. (2008). Ed. L.N. Berezhnova. SPb.

Timova, A.V. (2014). Non-linear educational process as the condition for higher education institution students' self-managing the knowledge. Pedagogical Sciences, 19. URL: http://novainfo.ru/article/1951

Wedman, J. \& Wang, F.-K. (2005). Knowledge management in higher education: A knowledge repository approach. Journal of Computing in Higher Education, 17(1), 116-138.

Yigit, M.F. (2017). Value Priorities of Public and Private University Students. Research in Social Sciences and Technology, 2(1). URL: http://ressat.org/index.php/ressat/article/view/38

Zianghirova, L.F. (2007). Retrospective analysis of the project method phenomenon in the foreign and Russian pedagogy. Bulletin of Bashkir University, 2(12), 111-114. 